\title{
North Coast of Africa
}

National Cancer Institute

\section{Source}

National Cancer Institute. North Coast of Africa. NCI Thesaurus. Code C77813.

Denotes a person having origins in a northern country of Africa such as Egypt, Sudan, Libya, Algeria, Morocco, or Tunisia. 